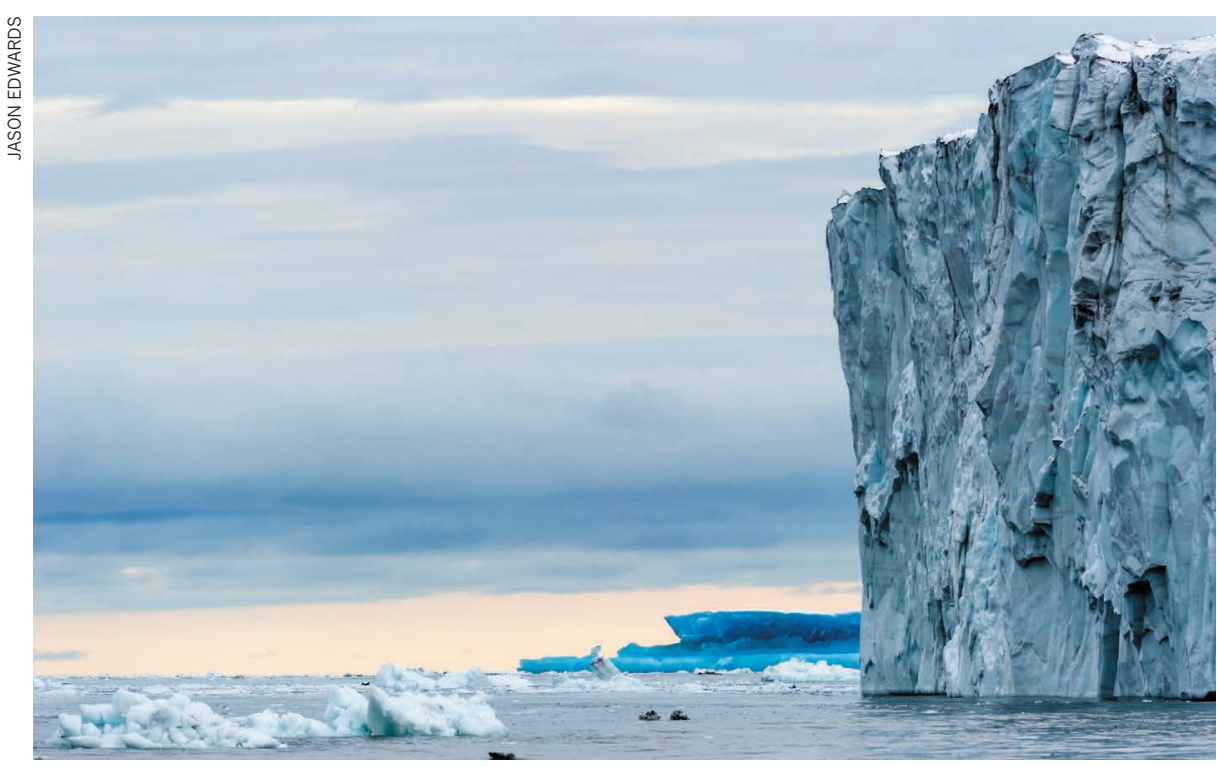

Antarctica's vast ice sheet and surrounding sea ice will be monitored by the NISAR satellite.

EARTH SCIENCE

\title{
Arctic scientists iced out by radar mission
}

\section{US-India satellite will focus on the Antarctic, upsetting some researchers who study northern ice.}

\section{BY ALEXANDRA WITZE}

$\mathrm{E}$ arth scientists in the United States have waited decades for NASA to launch a radar satellite to study natural hazards and changing ecosystems. But the design of a joint US-India radar mission planned for 2022 has divided researchers who study polar ice.

Mission managers at NASA and the Indian Space Research Organisation (ISRO) decided recently that the spacecraft, known as NISAR, will focus on the Antarctic at the Arctic's expense. That will essentially blind the mission to everything that lies above $77.5^{\circ} \mathrm{N}$ latitude, including most of the Arctic's rapidly shrinking sea ice - a decision that some researchers consider short-sighted. Several US polar scientists contacted by Nature declined to speak publicly about their concerns, worried about how NASA might react.

NASA and ISRO say they decided to focus on Antarctica in part because Europe's Sentinel-1 satellites already provide the same type of information, known as synthetic aperture radar (SAR), for the Arctic. The rationale is unusual for NASA, which rarely cites another satellite programme's work as a reason not to gather its own observations.

“They've made some tough choices," says Mark Drinkwater, head of the European Space

Agency's Earth and mission science division in Noordwijk, the Netherlands.

For scientists who study the cryosphere, SAR is important because it can see ice growing and changing through the long, dark polar night, when it is not visible to regular satellites, says Sinead Farrell, a sea-ice scientist at the University of Maryland in College Park.

Next month, NASA will begin using a specially equipped aeroplane to gather SAR data in the southeastern United States. The

\section{"That's the} issue: we have to either look at the north or look at the south." NISAR team will use the observations to fine-tune its data-processing algorithms.

NISAR will map the planet by measuring how radar signals bounce off Earth's surface. Radar reflections from directly beneath the spacecraft can be hard to interpret, so NISAR's two radar instruments will instead look off to one side. If the instruments point to the right, they can see the Arctic; if they point to the left, they can see the Antarctic. They cannot do both. "That's the issue: we have to either look at the north or look at the south," says Paul Rosen, the NISAR project scientist at NASA's Jet Propulsion Laboratory in Pasadena, California. Most other SAR missions are right-looking, which means that they cover the Arctic at the expense of the Antarctic. But last September, the NISAR science team decided to make its satellite left-looking for its entire primary mission, which is meant to last for at least three years. Word of the decision trickled out at events such as the American Geophysical Union meeting in Washington DC last December.

"NISAR will occupy a unique place in our international spectrum by being the only [SAR] mission that covers the Antarctic continent in its entirety," says Eric Rignot, a glaciologist at the University of California, Irvine, who is on the mission's science team. "This is tremendously important for our future," he argues, given that Antarctica is not mapped as well as is the Arctic, and climate change is transforming Antarctic ice, too.

SAR can track changes in glaciers flowing on and off land. In 2009, the Canadian Space Agency turned its RADARSAT-2 spacecraft temporarily to the left. The resulting SAR data helped Rignot and his colleagues to produce a detailed map of ice motion in Antarctica (E. Rignot et al. Science 333, 1427-1430; 2011).

\section{NORTHERN EXPOSURE}

NISAR will be physically able to look left or right. The mission's original plan called for the radar instruments to look right - to the Arctic — for about 300 days a year, and left - to the Antarctic - for about 60 days. But changing directions interrupts the gathering of data for other purposes, such as natural-hazard or ecosystem studies, says Gerald Bawden, NISAR's acting programme scientist at NASA.

Other, non-US SAR satellites do cover the north. Europe's twin Sentinel-1 satellites provide nearly complete SAR coverage of the Arctic every three days. Their data are openly available, and even archived on NASA's servers. The European Commission has committed to flying a series of Sentinel probes until 2030, which is the major reason NISAR scientists decided that they could abandon studying the Arctic. "This will be one of the first times NASA has considered the programme of record of other agencies," says Bawden.

But relying on other satellites for Arctic SAR coverage could be risky. The United States does not have a say in how Sentinel data are acquired, nor in the operations of three SAR satellites that the Canadian Space Agency plans to launch no earlier than March. The trio, called the RADARSAT Constellation Mission, will focus on the Arctic, and their data will be publicly available. NASA can also buy data from commercial SAR missions that focus on the Arctic, such as the small twin satellites launched last year by ICEYE of Espoo, Finland, but that can be expensive.

Amid all these Arctic data, Drinkwater says, focusing NISAR on the Antarctic is a good decision. "We'll have an observing-system capacity that can do both ends of the Earth in a routine monitoring fashion," he says. "We've never had that." - 